\title{
Student Perceptions Of Computer Hybrid Courses Across Three Disciplines: What Students Think About Hybrid Courses And What Type Of Delivery Format They Prefer
}

\author{
Daniel Gutierrez, (E-mail: dgutierrez@valenciacc.edu), Valencia Community College \\ Jane Wiese, Valencia Community College \\ Patricia Lopez, Valencia Community College \\ Nancy Portello, Valencia Community College \\ Anthony Beninati, Valencia Community College
}

\begin{abstract}
The present study examines student perceptions of computer hybrid courses across three primary disciplines: business, accounting, criminal justice/paralegal and those that identified themselves as belonging to other disciplines. Students $(n=94)$ were asked to respond to and rate twelve specific areas related to hybrid courses in which they were enrolled during the fall semester of 2003 at a community college located in the southern region of the United States. The courses consisted of required courses within each curriculum. Findings indicate that generally, course ratings were favorable; however, preference for enrolling in hybrid courses varied from discipline to discipline.
\end{abstract}

\section{Introduction}

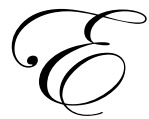

xtensive educational literature and research compares distance learning classes with traditional classes, including Veruin and Clark, (1991), Martin and Rainey, (1993), Souder, (1993), Beare (1989), McCleary and Egan (1989) and Neushauser, (2002). Each indicate that with just a few exceptions students that completed distance-learning courses have similar experiences to students who completed traditional face-to-face courses. Souder (1993) also found little differences in student outcomes when students in three different graduate level programs were compared. Kabat and Friedel, (1990), Heines and Hulse, (1996), Schutte, (1996), Bartlett, (1997), Bothun, (1998) however, indicate that student achievement varies and that students enrolled in distance learning classes achieved higher course grades than students enrolled in traditional courses. While these findings are mixed the debate continues as to which type of delivery format is best suited for academia and distance learning continues to flourish and change rapidly. One of the latest trends in distance learning to develop is the use of hybrid models (Young, 2002; Gutierrez, 2004). However, little research exists that examines this latest trend in delivering distance learning courses.

The concept of hybrid courses is relatively new (Young, 2002; Gutierrez, 2004) and appears to be the most recent trend in academia (Gutierrez, 2004). Because of the newness of this recently implemented delivery format, minimal research has emerged and only a hand full of studies exist that address this new method of delivering distance learning courses. In fact, in a review of the literature, Gutierrez (2004) discovered less than a dozen articles discussing the hybrid concept, and design or assessment of hybrid types. While more institutions are offering hybrid courses (Young, 2002; Gutierrez, 2004), the majority of research concerning distance learning classes involves classes taught entirely online or classes that consist of "older generation" types of distance learning formats 
(Gutierrez, 2004). This paper targets this void in the literature by examining student perceptions of hybrid courses in three primary disciplines: business, accounting, and criminal justice/paralegal majors.

\section{Research Focus/Methodology}

This study focuses on student perceptions of hybrid courses in three different disciplines: business, accounting, and criminal justice/paralegal. The two primary research questions we seek to answer are what students' perceptions of hybrid courses are and which type of delivery method they prefer: 1) traditional, 2) hybrid, 3) online or 4) telecourses.

Students enrolled in hybrid classes at a community college located in the southern region of the Unites States were surveyed near the end of the Fall Semester of 2003. A total of ninety-four students enrolled as business, accounting and criminal justice majors completed the surveys. Individual professors were asked to survey their courses only if it was designed and delivered as a hybrid, defined as a course that reduces traditional classroom "seat time" by $50 \%$ and supplements it with online learning activities. A total of four professors participated in the surveys. The survey instrument consisted of thirty-five questions, including questions about basic demographic data such as age, race, and marital status. The instrument also probed four general areas of concern that might impact teaching and learning. These areas included computer skill levels, levels of communication, course structure/content and organization. Students were asked to rate the course on twelve items. Four of the items consisted of ordinal measures and eight of the items utilized a scale measurement from one to ten, with ten being the highest score possible. Our goal was to determine what students thought about course lectures, assignments, exams, their computer skill levels as well as faculty members' skill levels who were teaching the course, levels of communication, course content/structure and organization and what students' perceptions were concerning how much they believed they learned while enrolled in these hybrid model courses.

Descriptive statistics in the form of percentages are calculated and reported for four of the measures that were ordinal in nature. Response choices for ordinal variables included not very relevant, somewhat relevant, very relevant and no opinion. For exam preparation, the wording varied slightly, utilizing seldom knew how to prepare, sometimes knew how to prepare, and knew how to prepare most of the time. For the other eight items, students were asked to assign a numerical value to the items, using a scale from one to ten, with ten being the highest score possible. A score of zero indicated that the student had no opinion. Mean scores and standard deviations were calculated for each of these eight items. In essence, these scores represent a grading scale with ten representing a $100 \%$ score or an achieved grade of "A". Finally, we asked students which type of course or delivery format they preferred. Choices included traditional courses (meeting all the time in class), hybrid courses (meeting fifty percent of the time in class and requiring fifty percent of the work to be completed online), online courses (delivered completely online), telecourses, and those that had no preference to any delivery format. Descriptive statistics for course preference type are also calculated and reported.

\section{Findings}

Generally speaking, students indicated that hybrid courses were well conducted and they appeared satisfied with the courses. Concerning course assignments and exams, $85 \%$ and $86 \%$ of the students indicted that assignments and exams were relevant to the course content being taught. Lectures and exams preparation however, received less favorable ratings, as $75 \%$ of the students thought that course lectures were relevant and $79 \%$ indicated that they knew how to prepare for exams. When we examined how students rated or graded the eight remaining items, all received a passing grade. The lowest ratings were students' own computer technology skills and their level of communication during the course. Students rated their computer skill levels at $75 \%$. For their level of communication, students rated themselves even lower at 70\%. Professors' computer skills and levels of communication were rated at $85 \%$ and $86 \%$, respectively. Course organization received an $80 \%$, while how much students thought they learned in the course and the academic standards for course received an $80 \%$ and an $83 \%$ respectively. Concerning students' overall learning experiences in the course, the hybrid courses received a rating of $78 \%$. 
Table 1 Student Perceptions Regarding Course Content \& Structure

\begin{tabular}{|l|c|c|c|c|}
\hline & Not Relevant & $\begin{array}{c}\text { Somewhat } \\
\text { Relevant }\end{array}$ & Very Relevant & No Opinion \\
\hline Course Lectures & $1.1 \%$ & $12.9 \%$ & $75.3 \%$ & $10.8 \%$ \\
\hline Course Assignments & $1.1 \%$ & $9.7 \%$ & $84.9 \%$ & $4.3 \%$ \\
\hline Course Exams & $0 \%$ & $8.5 \%$ & $86.2 \%$ & $5.3 \%$ \\
\hline Exam Preparation & $\begin{array}{c}\text { Seldom knew how } \\
\text { to prep for exams }\end{array}$ & $\begin{array}{c}\text { Sometimes knew } \\
\text { how to prepare }\end{array}$ & $\begin{array}{c}\text { Most of the time knew } \\
\text { how to prep }\end{array}$ & \\
\hline
\end{tabular}

Table 2 Student Ratings for Hybrid Courses

\begin{tabular}{|l|c|c|}
\multicolumn{1}{|c|}{ Response Items } & $\begin{array}{c}\text { Mean } \\
\text { Score }\end{array}$ & $\begin{array}{c}\text { Standard } \\
\text { Deviation }\end{array}$ \\
\hline Rate your level of computer skills. & 7.46 & 1.86 \\
\hline Rate your instructor's level of computer skills. & 8.45 & 1.55 \\
\hline Rate your own level of communication \& feedback during the course. & 7.05 & 1.89 \\
\hline Rate your instructor's level of communication \& feedback during the course. & 8.61 & 1.64 \\
\hline How well was the course organized? & 8.00 & 2.08 \\
\hline How much did you learn in the course? & 8.01 & 1.89 \\
\hline Rate the academic standard in the course. & 8.33 & 1.58 \\
\hline Rate your overall learning experience in the course. & 7.88 & 1.96 \\
\hline
\end{tabular}

The final area of interest we examined was what type of delivery format students would prefer to take. Overall, students indicated that they preferred traditional courses as the primary method of delivery. $48.4 \%$ of the students in the sample indicated they preferred traditional courses while $35.5 \%$ indicated they preferred hybrid courses and $12.8 \%$ indicated they had no preference. Surprisingly, only $3.2 \%$ of the sample indicated that they preferred courses that were completely online.

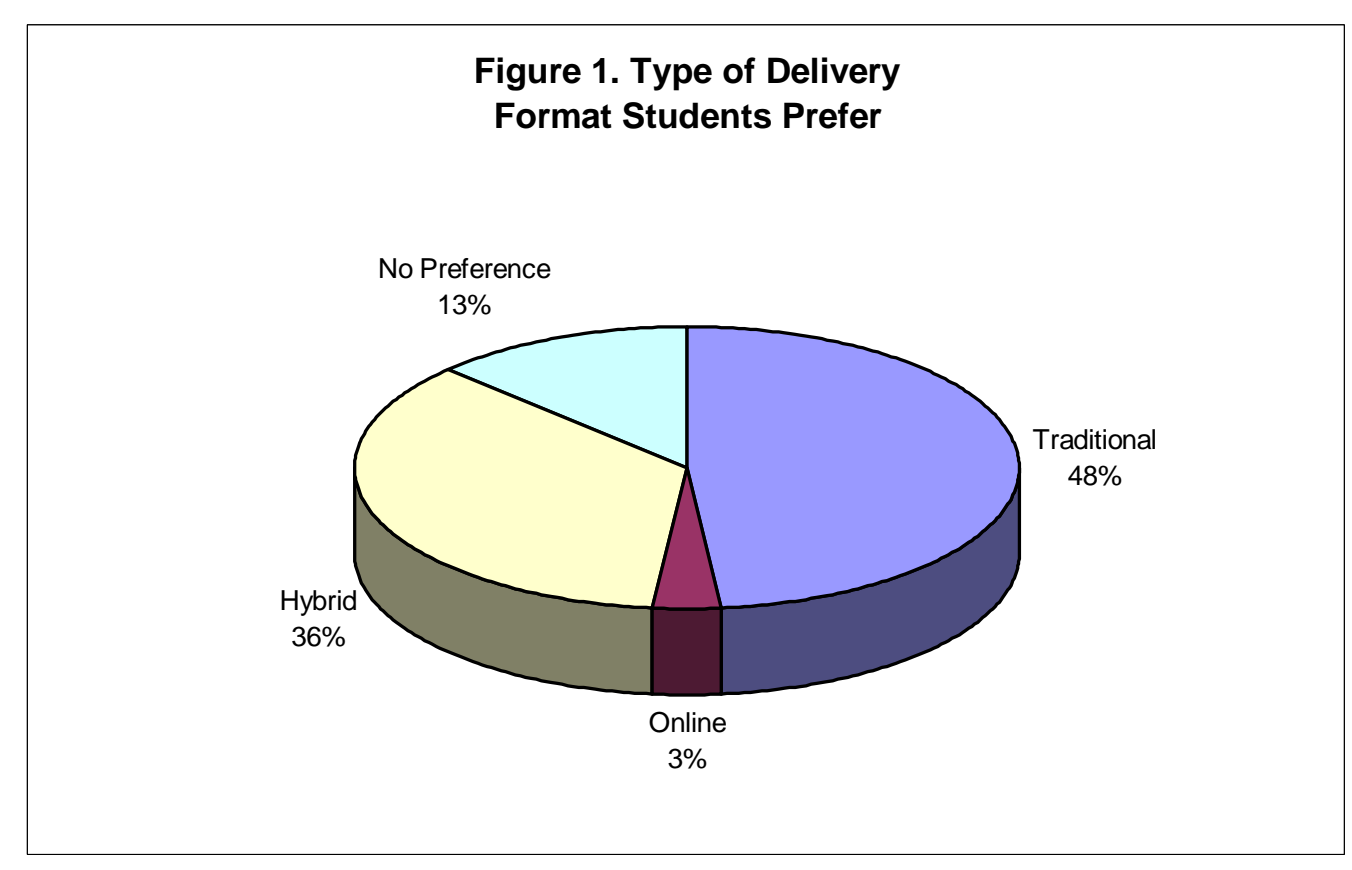


A different picture emerged upon examining what type of course students preferred on a discipline-bydiscipline basis. Students that were criminal justice/paralegal majors expressed a higher preference for hybrid courses than business, accounting and those classified as belonging to other majors. Students surveyed in the criminal justice classes had a $61 \%$ preference rate for hybrid course, while only $20 \%$ of business majors and $23.5 \%$ of the accounting majors preferred hybrid courses. Overall, business and accounting majors had the lowest preference for hybrid classes. Students that identified themselves as belonging to other majors also indicated a higher preference rate. $44.4 \%$ of the students from other disciplines or majors indicated they preferred hybrid courses over other forms of delivery.

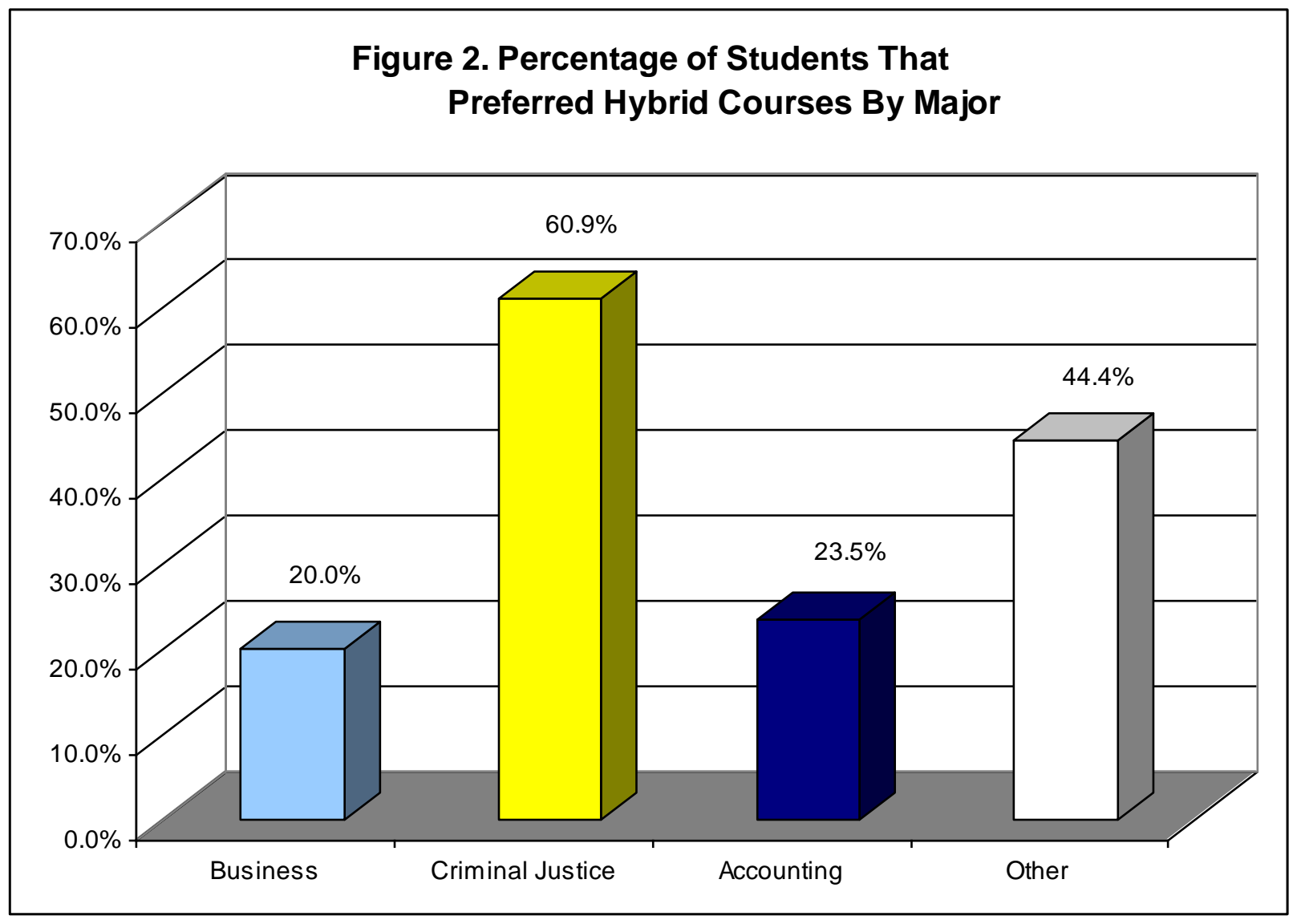

\section{Discussion/Limitations}

Delivery of academic courses using hybrid models is the latest trend on campuses across this country (Young, 2002; Gutierrez, 2004). However, research concerning this newly adopted delivery format is at best scant (Gutierrez, 2004). Our purpose here was to investigate student perceptions regarding this particular delivery format and to have students rate the courses they were enrolled in during the current semester in order to gain an understanding of their perceptions of hybrid models. We also wanted to determine which type of delivery format students preferred (traditional courses, online course, telecourses or hybrid courses.) Overall, hybrid courses received favorable ratings in all the areas we probed. When we examined the overall grade students assigned the eight items that were scored on a scale that could be graded, hybrid courses earned a passing grade of $82 \%$, or a "B" grade. While the hybrid courses received favorable grades overall, students indicated that they preferred traditional courses more than they preferred hybrid courses, $48.4 \%$ versus $35.5 \%$, respectively. Surprisingly, courses that are 
offered completely online received a very low preference rating, with only $3.2 \%$ of the students indicating they preferred this type of delivery format. Between business, accounting and criminal justice majors, dramatic differences in preferences emerged. The most striking revelation was the fact that criminal justice majors preferred hybrid courses at a rate three times higher than business and accounting majors.

One possible explanation for higher preference ratings among criminal justice majors may be attributed to individual instructor differences. When we examined individual professor ratings, we discovered that the criminal justice professor received the highest student ratings in five of the six categories. As a result of these finding, our study of student perceptions of hybrid courses concluded with a brief reflective exercise concerning our teaching histories with distance learning and hybrid courses. Of the four faculty members that surveyed their hybrid courses, only one had experience teaching online classes and more specifically, hybrid courses. For three of the four faculty members, this was their first time teaching any type of distance learning course, including hybrid courses. The fourth professor in the equation however, has been developing and teaching hybrid courses for more than three years. It seems clear that this factor may have a substantial impact on these findings.

Throughout the academic year, administrators must make decisions concerning course offerings and how they are to be delivered. These decisions are sometimes made without consideration to the ramifications that might occur if certain variables are not taken into consideration. In this particular case, some of the course offerings were offered in hybrid format because they were identified as "high demand" courses by the college with enrollments of $100 \%$ plus. Lack of resources (available rooms) coupled with the desire to meet student demands persuaded administration to offer these courses as hybrid courses. Hybrid courses can be administratively seductive because they can be cost-effective. When resources are limited and classroom space is an issue, as was in this case, hybrid courses appear appealing because two different classes can be offered at the same date and time utilizing the same room. It is important to remember however, that hybrid classes must be well thought out, organized, and planned. They should not be offered simply for the college's convenience. If so, they may compromise the integrity of academic standards, learning, and student and faculty morale. They should not be viewed as just administrative conveniences. They must be viewed as a complex dynamic of teaching pedagogies that could have serious negative implications if they are offered without serious consideration of faculty preparedness.

Another possible explanation that could explain these differences is the nature of course content, a dimension we have not explored here. This raises the question of whether or not some courses may be better suited for a hybrid delivery format than others. A sound inference would be that instructional skills, course content, and learning outcomes set for each course should shape the choice of instructional delivery formats. Two final explanations that also need to be explored are student learning styles and teaching styles - the extent that students' learning styles and individual teaching styles have an impact on how students perceive hybrid courses.

While we have examined student perceptions of hybrid courses across three disciplines and answered our initial research questions concerning how students perceived hybrid courses and any preferential differences that exist, more questions have emerged that beg further research. Additional research concerning hybrid courses should be forthcoming and will enable academicians and administrators to assess the viability and learning effectiveness of this new delivery model.

\section{References}

1. Bartlett, T. (1997). The Hottest Campus on the Internet. Business Week, 77-80.

2. Beare, P. L. (1989). The Comparative Effectiveness of Videotape, audiotape, and telecture. The American Journal of Distance Education, 3, 2, 57-66.

3. Bothun, G. D. (1998). Distance Education: Effective Learning or Content-free Credits? Cause/Effect, 21, 2, 28-37.

4. Gutierrez, D. (2004). A Comparative Study Between A Traditionally Taught Criminology Course And A Computer Hybrid Course: Does Technology In The Classroom Make A Difference? Paper presented at the College Teaching \& Learning Conference, Lake Buena Vista, FL, January, 2004.

5. Heines, R. A., and Hulse, D. B. (1996). Two-way Interactive Television. The American Journal of Distance Education, 3, 1, 50-60. 
6. Kabat, E. J., and Friedel, J. (1990). The Development, Pilot-testing, and Dissemination of a Comprehensive Evaluation Model for Assessing the Effectiveness of a Two-way Interactive Distance Learning System. Davenport, Iowa: Eastern Iowa Community College. (ERIC Document Reproduction Service No. ED 332 690).

7. Lago, M. E. (November 2000). The Hybrid Experience: How Sweet It Is! Converge Magazine. Retrieved October 10, 2003 from http://www.convergemag.com/ Publications/CNVGNov00/hybrid/index.shtm

8. Leh, A. S. (2002). Action Research on Hybrid Courses and their Online Communities. International Council for Education Media, 31-38.

9. Martin, E. E., and Rainey, L. (1993). Student Achievement and Attitude in a Satellite-delivered High School Science Class. The American Journal of Distance Education, 7, 1, 54-61.

10. McCleary, I. D., and Egan, M. W. (1989). Program Design and Evaluation: Two-way Interactive Television. The American Journal of Distance Education, 3, 1, 50-60.

11. Moore, M. G., \& Kearsley, G. (1996). Distance Education: A Systems View. Belmont, CA: Wadsworth Publishing Company.

12. Neuhauser, C. (2002). Learning Styles and Effectiveness of Online and Face-to-Face Instruction. The American Journal of Distance Education, 16, 2, 99-113.

13. Schutte, J. G. (1996). Virtual Teaching in Higher Education: The New Intelectual Superhighway or Just another Traffic Jam?

14. Sherry, L. (1996). Issues in Distance Learning. International Journal of Educational Telecommunications, 1, 4, 337-365.

15. Souder, W. E. (1993). The Effectiveness of Traditional vs. Satellite Delivery in Three Management of Technology Master's Degree Programs. The American Journal of Distance Learning, 7, 1, 37-53.

16. Veruin, J. R., and Clark, T. (1991). The Foundations of Effective Practice. San Francisco: Jossey-Bass.

17. Young, J. R. (22, March 2002). Hybrid Teaching Seeks to End the Divide Between Traditional and Online Instruction. Chronicle of Higher Education, Vol. 48, 28, A33-1c. Retrieved October 5, 2003 from http://chronicle.com/free/v48/i28/ 28a03301.htm. 